\title{
Concomitant changes in the Environment and small pelagic fish community of the Gulf of Lions
}

Feuilloley Guillaume ${ }^{1}$, Fromentin Jean-Marc ${ }^{1}$, Stemmann Lars ${ }^{2}$, Demarcq Herve ${ }^{5}$, Estournel Claude ${ }^{3}$, Saraux Claire ${ }^{1,5}$

${ }_{1}^{1}$ MARBEC, Univ. Montpellier, Ifremer, IRD, CNRS, Sète, France

2 LOV, Observatoire Océanologique, UMR7093, UPMC Univ Paris 06, 06234 Villefranche/mer, France

3 Laboratoire d'Aérologie, Univ Toulouse, CNRS, UPS, UMR 5560, 31400 Toulouse, France

${ }^{4}$ IPHC, Univ Strasbourg, CNRS, 7178, DEPE, 67000 Strasbourg, France

${ }^{5}$ MARBEC, Univ. Montpellier, Ifremer, IRD, CNRS, Sète, France

\begin{abstract}
:
An important decrease in small pelagic fish condition and size has been observed in the most productive ecosystem of the Mediterranean Sea, the Gulf of Lions, since 2008, leading to an important fishery crisis. Previous studies suggested bottom-up control to be the most probable cause for these changes. Here, we investigate whether an environmental change might have caused such a situation. In the absence of zooplankton time series, this study aims at describing temporal changes in key abiotic factors for the planktonic and fish production of the Gulf of Lions, such as SST, meso-scale fronts, wind-induced coastal upwelling, river discharge, water stratification and deep convection and then at understanding potential link on Chl-a concentration as well as small pelagic fish populations. Our results indicate that the environmental conditions have broadly changed in the Gulf of Lion, with a major change in the mid-2000s, affecting the Chla concentration (which showed a regime shift in 2007), but also the SST, the upwelling and frontal activities, the Rhone river discharge (and particularly the $\mathrm{N}$ and $\mathrm{P}$ nutrients inputs) as well as the deep winter convection. Those changes could have affected the plankton production and consequently the small pelagic fish community that displayed similar patterns of variations as the environmental conditions.
\end{abstract}

\section{Highlights}

- Rhone river nutrients concentrations significantly decreased since 1990. Rhone river inputs are the main driver of Chl-a in the Gulf of Lions shelf area. Changes were observed in the environment and small pelagic fish population in mid 2000s. Small pelagic community and environmental system of the Gulf of Lions presented the same patterns of variation. 
Keywords : Environmental change, Bottom-up control, Chlorophyll-a, Small pelagic fish, Northwestern Mediterranean Sea 


\section{INTRODUCTION}

Small pelagic fish play a key role in regulating ecosystems, by providing energy and nutrient transfer from low (plankton) to high trophic levels (top predators, Cury et al., 2000; Larkin, 1996). Nonetheless, small pelagic fish populations are known for their important fluctuations and therefore understanding how they might be controlled by lower trophic levels (phyto- and zoo-plankton) and the abiotic environment is of primary importance (Schwartzlose \& Alheit, 1999). This is especially true in a context of both climate change and important socio-economic stakes, as small pelagics are the most commonly fished species (Lindegren et al., 2013).

As plankton is closely related to abiotic environment, environmental changes can modify plankton phenology, biomass or community composition and then impact plankton feeders, such as small pelagic fish (Alheit \& Niquen, 2004; Rykaczewski, 2018). In the Northwest Pacific for instance, changes in temperature and upwelling strength can delay the phytoplankton bloom and impact zooplankton size (Kudela et al., 2006). Such changes are known to directly affect small pelagic fish recruitment and subsequently fish population size either positively (match) or negatively (mismatch) (Cushing, 1990). In the sea of Japan, delays in the spring bloom have increased the temporal overlap with sardine larvae, resulting in higher recruitment of the Japanese sardine (Kodama et al., 2018). Similarly in the Barents sea, variations in zooplankton biomass induced by changes in currents and winds regime, affected both the growth rate and recruitment of capelin (Skjoldal et al., 1992). These examples show how environmental parameters often affect plankton dynamics and in turn small pelagic fish populations.

Changes in the small pelagic community were recently described in the NW Mediterranean Sea, and in particular in the Gulf of Lions ( Saraux et al., 2019; Van Beveren et al., 2014). There, three main small pelagic fish species are present. Two of them, the European pilchard Sardina Pilchardus and the European anchovy Engraulis encrasicolus are targeted by 
commercial fisheries, while the other, the sprat Sprattus sprattus is not. Since 2008, landings of small pelagics have sharply decreased reaching their lowest values in 150 years (Van Beveren et al., 2016). Fishermen indeed stopped fishing these species because of the absence of market for fish being too small and too skinny (Van Beveren et al., 2014, Saraux et al., 2019). Crashes in small pelagic fish landings and abundance have often been observed worldwide, generally due to environmentally-driven recruitment ( Toresen \& Østvedt, 2000; Barange et al., 2009; Chambers \& Trippel, 2012). However, the Gulf of Lions case is different. Indeed, the decrease in size resulted from the combination of a lower growth and the disappearance of the oldest and largest individuals, but the recruitment was maintained (or even increased), due to an earlier sexual maturity (Brosset et al., 2016). Interestingly, sardine and anchovy abundance have slightly increased since 2008 , but their biomass did not because of lower body condition, mean length and weight (Van Beveren et al., 2014). Different hypotheses have been formulated and investigated to understand this unusual phenomenon, but top-down controls (fishing or natural predators), emigration of largest individuals, or diseases have all been refuted (Queiros et al., 2018; Saraux et al., 2019; Van Beveren et al., 2016; Van Beveren et al., 2017). Even if a cocktail effect of some of the above pressures cannot be excluded, the hypothesis of a bottomup control has been suggested as the most probable underlying mechanism (Saraux et al., 2019). Brosset et al., (2016) suggested that both sardine and anchovy maintained high reproductive investments after 2008 despite their decrease in body condition, so that their survival during reproduction or just after may be impaired and highly dependent on prey availability. Sardine, anchovy and sprat mostly feed on zooplankton (Brosset et al., 2016; Costalago et al., 2012), so a decrease in abundance and/or in quality of zooplankton could explain the observed decrease in body condition and growth and increased mortality after the reproduction period (Saraux et al., 2019). Brosset, et al., (2016) found changes in small pelagics diet before and after 2008, based on stomach content and stable isotope analyses, with smaller plankton species consumed 
after 2008. However, zooplankton data remain scarce in this area, so bottom-up control could not be directly validated through the analysis of zooplankton time series.

The aim of this study was therefore to investigate this hypothesis of bottom-up control, using Chl- $a$ satellite data, as a proxy of phytoplanktonic biomass and various oceanographic variables of interest to detect potential co-variation pattern with small pelagic fish. In the Gulf of Lions, three main oceanographic processes are known to play a role in phyto- and zooplanktonic production over the continental shelf : the Rhone river inflows, wind-induced coastal upwellings and the Northern current (Millot, 1979, 1990; Salat, 1996). The Rhone River is indeed an important source of terrestrial nutrients such as $\mathrm{N}$ and $\mathrm{P}$ and suspended matter (Lefevre et al., 1997; Macias et al., 2018), its plume flowing mainly south-westward, but also sometimes drifting to the West side and along the coast (Demarcq \& Wald, 1984; Fraysse et al., 2013). The area is also governed by strong northerly winds, the Mistral and Tramontane, that induce coastal upwellings which upwell deeper waters towards the surface, contributing to local phytoplankton bloom (Millot, 1979). At the shelf border, the Northern Current, which flows from east to west can, under certain climate conditions, produce meanders which penetrate onto the shelf and impact the biogeochemistry (Millot, 1999; Petrenko, 2003; Ross et al., 2016). Indeed, the Northern current is an oligotrophic current which can negatively affect the phytoplanktonic biomass on the shelf during intrusions modifying concentration of nutrients (Petrenko, 2003; Ross et al., 2016). On top of these variables, we also investigated other phenomena potentially important for phytoplankton production such as thermal fronts, the stratification of the water column and deep winter convection. Finally, the WeMO index (Martin-Vide \& Lopez-Bustins, 2006) was also studied to have a broader vision of the system. Indeed, large scale variables are more integrative and sometimes allow to better predict animal populations than local environmental variables (Stenseth et al., 2003; Stenseth \& Mysterud, 2005). If those process are known and there role for primary production have already been 
demonstrated in the literature, no quantification of their importance is available. Indeed, the relative contribution of each have never been studied and particularly on long-term inter-annual variability. As the objective was to investigate whether recent changes in small pelagic fish population may result from bottom-up processes, we further examined the temporal changes in the body condition, abundance, biomass and mean size of sardine, anchovy and sprat over the same period and compared the main patterns of (co)variations of the environmental variables with those of the small pelagic fishes.

\section{MATERIAL AND METHODS}

\subsection{Environmental data}

All environmental variables were computed and averaged over the continental shelf, delimited by the $200 \mathrm{~m}$ isobaths (blue area on Fig 1) except the deep winter convection index which was calculated by (Herrmann et al., 2017) in the open ocean, and the Chl- $a$ concentation in the Northern current which was averaged in the beige area in the Ligurian sea (Fig 1). Different size area were tested for the Ligurian Chl- $a$ time series, avoiding the spring bloom area which is more productive but separated from the Northern Current, and identical results were obtained regardless of the area defined. From each environmental variable (except for the deep convection and stratification, see below), annual values were derived averaging from September (year t-1) to August (year t) monthly data in order to integrate processes which mostly spread throughout the winter period (i.e. November to March), such as the coastal upwellings or the Rhone river outflow. 


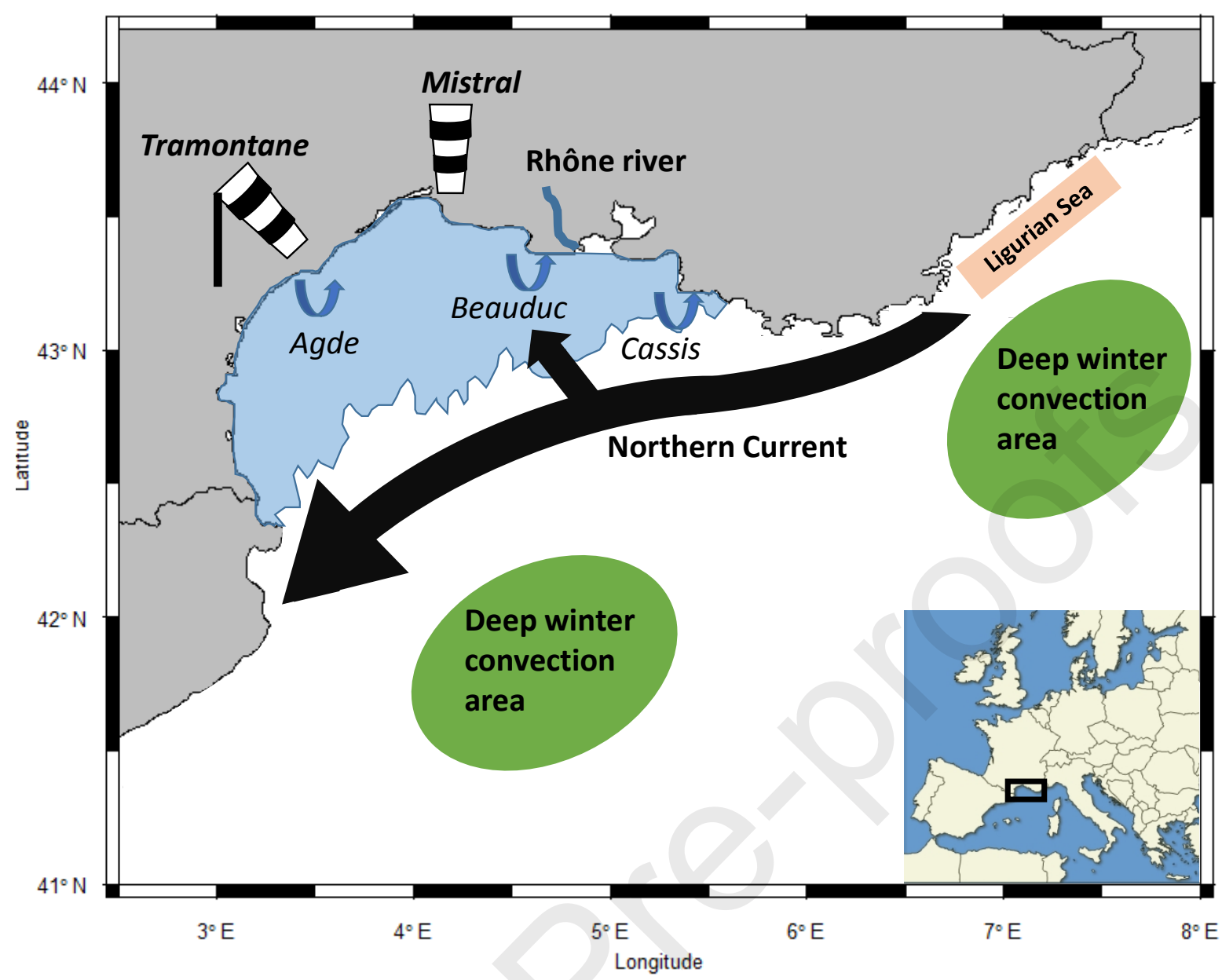

Figure 1: Map of the Gulf of Lions and its main oceanographic characteristics. The blue area represents the continental shelf until the $200 \mathrm{~m}$ isobaths. Coastal curved arrows indicate the upwelling areas defined in (Millot, 1979) (Agde to the West, Beauduc in the middle and Cassis to the East). The black arrow is the Northern Current, with the thin arrow indicating possible intrusion onto the shelf. Mistral and Tramontane are the main northerly winds. The green areas indicate the deep winter convection cells and the beige area is the Ligurian sea surface used to calculate Chl-a concentration.

\subsubsection{Rhône river}

$\mathrm{N}$ and $\mathrm{P}$ nutrient concentrations in the Rhone River were measured at the Arles station, either monthly from 1990 to 2004 and 2014-2017 or daily from 2005 to 2013. Monthly time series were constructed and the impact of the change of resolution in the samples was checked. A change in the variance was observed in 2004, but not in the mean value and no discontinuities 
were observed at this period in further analyses from both series. The river flow was measured at Beaucaire station and covered the period 1960-2017 at a daily resolution. Those data are available on (http://www.hydro.eaufrance.fr). $\mathrm{N}$ and $\mathrm{P}$ nutrient inputs were also studied, multiplying nutrient concentration by the river flow.

\subsubsection{SST}

Sea surface temperature (SST) was estimated using the Advanced Very High Resolution Radiometer (AVHRR) daily data from 1982 to 2017 at a 4km resolution, obtained on the NASA platform (https://data.nodc.noaa.gov/pathfinder/Version5.3/L3C/). For each pixel, the maximum value between day and night was kept. Because the original criteria available for the cloud masking were not satisfying for our study area, a specific mask has been generated for each daily data using the departure from a monthly climatology, considering a variable threshold according to temporal variability of the SST at each pixel. A monthly SST time series was then built over the continental shelf, until the $200 \mathrm{~m}$ isobaths, averaging all the data available during each month.

\subsubsection{Thermal fronts}

Thermal fronts between two water masses of different temperatures can locally increase nutrient concentration and phytoplanktonic biomass when convergent (Bakun, 2006; Franks, 1992; Woodson \& Litvin, 2015). Thermal fronts were detected with the Single Edge Detection algorithm based on a bimodal histogram in order to detect the presence of two water masses, initially developed by Cayula \& Cornillon, (1992) and modified by Roa-Pascuali et al., (2015). This algorithm is not based on the direct measurement of a local gradient and is therefore particularly suitable for remote sensing data where the SST of numerous pixels is biased by various atmospheric artifacts that correspond to false local high gradients, which would be otherwise considered as fronts. For each daily frontal pixel previously computed, the local 
Sobel gradient is separately computed and a gradient threshold of $0.042^{\circ} \mathrm{C} \cdot \mathrm{km}^{-1}$ was used to select the strongest fronts, more likely associated to major physical processes (Roa-Pascuali et al., 2015). A monthly front index was constructed as the ratio between the sum of all gradient values where fronts were detected in the entire month and the total number of pixels of available SST in the month.

\subsubsection{Chl-a}

Chl- $a$ concentrations were estimated using L3 daily data from SeaWiFS Aqua portal at 9km resolution from 1998 to 2002 and L3 daily data from MODIS Aqua portal at 4km resolution from 2003 to 2017 (https://oceancolor.gsfc.nasa.gov/13/order/). Anomalous high values of concentration were detected at very coastal pixels and in the Rhone plume. These were thought to derive from turbidity i.e. water belonging to the "case 2 " optical properties as defined by (Morel \& Prieur, 1977), generally not compatible with the fluorescence to concentration algorithm (Gohin, 2002; Gohin et al., 2005). As such, concentration data were truncated to a maximum value of $5 \mu \mathrm{g} / \mathrm{L}$, allowing to keep high but reasonable values and so to avoid any potential overestimation of the Chl- $a$ concentration on the shelf. No problem of compatibility was detected between the two satellites, as time series from MODIS and SeaWiFS were highly similar during their common period of use, i.e. 2003-2006 (slope $=0.95$, intercept $=-0.02$, $\left.\mathrm{R}^{2}=0.96\right)$.

\subsubsection{Deep winter convection}

Deep winter convection occurs when a dry and cold wind blows during several days and induces a decrease in SST and an increase in salinity due to evaporation, leading to an increase of the surface water density. This water dives and a convection phenomenon starts (Herrmann et al., 2017). In the deep winter convection area, outside the shelf, important spring blooms are observed (Herrmann, et al., 2013; Herrmann, et al., 2014). Whether these deep convections can 
influence the phyto- and zooplanktonic production on the shelf remains unknown, but worth to be investigated. To incorporate the convection in our analysis, we used the annual deep winter convection time series in NW Mediterranean Sea calculated by Herrmann et al. (2017). This series covered the period 1998-2016 and represented the maximum volume of mixed water, obtained from both altimetry and ocean colour satellite data. Indeed, volume of mixed water was estimated by numerical modelling and linear regression was performed between volume of mixed water, surface Chl- $a$ concentration and sea level anomaly to establish relationships by means of regression parameters. The time series of volume of mixed water could then be extended after the end of the numerical runs (in 2013) with Chl- $a$ satellite concentration, satellite sea level anomaly and the regression parameters estimated. Because this process occurs only in winter, no monthly time series was available.

\subsubsection{Upwelling}

The upwelling index was calculated from CCMP (Cross Calibrated Multi-Platform) L3 wind daily data with a resolution of $1 / 4^{\circ}$, provided by the Remote Sensing System (http://www.remss.com/measurements/ccmp/). This dataset combines satellite data, moored buoy wind data, and ERA-Interim model wind fields. The index was based on Ekman transport ( $\left.\mathrm{T}_{\mathrm{ek}}\right)$ (Bakun, 1996; Caverivière \& Demarcq, 2002). With the action of the Coriolis strength, the wind blowing parallel to the coast transports water on the right (in the Northern Hemisphere) perpendicularly to the coast. The Ekman index was computed by dividing the coastal trait into segments (sensitivity analyses showed similar results regardless of the resolution used for the pixels and results are presented for 1/16 degree resolution). Then, in each pixel, the wind component parallel to the coast was calculated and used to apply the Ekman equation to estimate the volume of water upwelled with: 
$\mathrm{T}_{\mathrm{ek}}=\frac{C P^{2} * \rho_{\text {air }} * c d}{2 * \Omega * \sin (\text { lat }) * \rho_{\text {eau }}} * \mathrm{~L}_{\text {coast }}$

where $\mathrm{CP}$ is the wind component parallel to the coast, $\rho_{\text {air }}=0.0012, \rho_{\text {eau }}=1.027, \mathrm{~cd}=0.013$ the drag coefficient, $\Omega=7.14 \mathrm{e}^{-5}$ the angular velocity of Earth, lat the latitude and $\mathrm{L}_{\text {coast }}$ the length of coastal trait. Upwelling indices were then built using the sum of water volume upwelled from all coastal pixels over the entire Gulf of Lions.

\subsubsection{Stratification}

The stratification index was estimated using temperature and salinity outputs from NEMO model provided by CMEMS (http://marine.copernicus.eu/services-portfolio/access-toproducts/) from the MEDREA re-analysis (Simoncelli et al., 2014). Water density was then calculated at each depth layer of the model with the Equation of Sea water EOS-80 (UNESCO, 1981) and stratification estimated as follow:

Stratification $=\int_{Z}^{0}(d(Z)-d(z)) d z$

With $d(Z)$ the bottom density, $d(z)$ and dz respectively the density and the thickness of layer $z$ (Estournel et al., 2016). Regarding the stratification index, the annual maximum value rather than the mean was kept, because this series of maximum contained most of the variance. As maximal stratification usually occurred in August, i.e. at the end of our year period (the other annual time series were constructed by averaging monthly data from September year t-1 to August year t), the Stratification time series was lagged by one year, so that we could thus examine a potential effects of stratification on the other environmental variables or the biological variables (the latter being sampled in July of each year, see above). 


\subsubsection{Western Mediterranean Oscillation (WeMO)}

The WeMO index was preferred to others such as the NAO because of its stronger capacity to represent NW Mediterranean Sea environmental conditions (Martin-Vide \& Lopez-Bustins, 2006). This index represent differences in standardized surface atmospheric pressure between San Fernando (Spain) and Padua (Italy) and integrate fluctuations in rainfall, river flow, wind mixing and temperature. Positive values of the index are associated to lower temperature and higher river flow and wind mixing, though to be favourable for plankton productivity (Martin-Vide \& Lopez-Bustins, 2006; Martín et al., 2012). The annual index was preferred to the winter index as it has already been shown to have an importance for small pelagic variability in the NW Mediterranean Sea (Brosset et al., 2015; Martín et al., 2012). The WeMO monthly data were downloaded on the University of East Anglia website (https://crudata.uea.ac.uk/cru/data/moi/).

\subsection{Biological data}

Small pelagic fish data were obtained during the PELMED scientific survey (Bourdeix \& Hattab, 1985), which has occurred every July since 1993. The aim of this survey is to assess the stock size of anchovy, sardine and sprat in terms of abundance and biomass, using acoustic detection and identification trawls in the Gulf of Lions. Acoustic detection is performed along 9 parallel transects, covering the shelf from the coast to the edge (20-200m isobaths). Acoustic data were recorded every $1 \mathrm{~nm}$ using multi-frequency echosounders (Simrad EK500 and ER60), while travelling at a constant speed of $8 \mathrm{~nm} \cdot \mathrm{h}^{-1}$.Energies from the $38 \mathrm{kHz}$ frequency were used to estimate fish energy. Species discrimination and echo-partitioning were performed based on trawl composition conducted along the transects. Species biomass and abundance were finally estimated from species energy using specific target strength $(\mathrm{TS}=20 \log (\mathrm{L})-71.2$, where $\mathrm{L}$ is the length of the fish for all 3 species (Doray, 2012; Saraux et al., 2014). Depending on the 
year, between 20 to 50 trawls were conducted in July over all the shelf. Individuals were randomly sampled from the trawls to take measurements such as weight, length and gonad maturity. As the species exhibited an allometric growth pattern (Brosset et al., 2015; Van Beveren et al., 2014), body condition was estimated with the Le Cren index (Le Cren, 1951) which also avoid a potential length effect (Brosset et al., 2015). The index was expressed as :

$$
\mathrm{Kn}=\frac{\mathrm{W}}{\mathrm{Wr}}
$$

With $\mathrm{W}$ the observed weight and $\mathrm{W}_{\mathrm{r}}$ the theoretical weight of an individual calculated with

$\mathrm{W}_{\mathrm{r}}=\alpha \mathrm{L}^{\beta}$, where $\alpha$ and $\beta$ are the regression parameters of the length-weight relationship with $\alpha=3.86 \times 10^{-3}, 5.90 \times 10^{-3}$ and $3.21 \times 10^{-3}$ and $\beta=3.20,3.10$ and 3.37 for anchovy, sardine and sprat respectively (Van Beveren et al., 2014). Finally, 4 variables were available for each species: abundance, biomass, mean size and mean body condition index. These variables were all estimated from the PELMED survey, thus representing the summer situation (July) and intraannual variability could not be estimated.

\subsection{Statistical analyses}

All the analyses presented above were conducted with R v. 3.4.1 (R Core Team, 2018).

\subsubsection{Univariate time series analyses}

Analyses were conducted for both monthly and annual time series of each environmental variable. Because monthly time series presented both inter-annual and intra-annual variability, seasonal cycle and intra-annual variability were highlighted with contour plot of monthly time series, while trends were studied after a 5 year smooth with loess in order to remove seasonal variation (Fig 2). To investigate inter-annual variability, breakpoints analyses were computed on annual time series, using the strucchange package and an algorithm testing structural changes 
in time series (Kleiber et al., 2002). Optimal number of segment partition was based on BIC criterion in order to compute only the most relevant changes.

\subsubsection{Multivariate analyses}

Climatological time series were also constructed, representing the mean value of each month, so as to investigate seasonality patterns. In order to investigate the seasonality of the whole environmental system of the Gulf of Lions, principal component analyses (PCA) were run on correlation matrices of climatological time series (i.e the mean value of each month during the entire period), for SST, Chl- $a$, stratification, thermal front, nutrient concentration and Rhone outflow time series.

\subsection{Modelling the Chl- $a$ concentration}

To identify the environmental variables that would be related to the variability in interannual Chl- $a$ concentration, a generalized linear model (GLM) was applied on the annual time series, using a Gaussian family and a log link. Explanatory variables represented processes known in the literature to modify nutrient availability and affect phytoplanktonic production, i.e., the upwelling index, the winter convection index, the thermal front index, concentration of $\mathrm{N}$ and $\mathrm{P}$ and the Rhone river flow. The concentration of Chl- $a$ in the Ligurian Current as well as the WeMO index were also considered because of their potential impacts on plankton production (see above). Because, $\mathrm{N}$ and $\mathrm{P}$ nutrient inputs were strongly correlated with the Rhone outflow, it was not possible to consider them in a single model. Two similar GLMs were thus built with all previously mentioned variables, as well as (i) the Rhône river flow and the two time series of $\mathrm{N}$ and $\mathrm{P}$ nutrient concentrations (case 1) and (ii) $\mathrm{N}$ and $\mathrm{P}$ nutrient inputs instead of nutrient concentrations and Rhone river flow (case 2). In both GLMs, a stepwise forward and backward selection was run to select the most explanatory and significant variables based on AICc. Multicollinearity between variables was checked by computing Variance Inflation Factor 
(VIF). Finally, residuals and the goodness of fit of the model were checked to evaluate the quality of the model.

\subsection{Dynamic Factor Analysis}

Dynamic Factor Analysis (DFA) is a multivariate time-series technique used to identify $M$ hidden common trends in a set of $N$ time series and that could further estimate the effects of explanatory variables in a biological time-series data set (Zuur et al., 2003). The time series are modelled as a linear combination of different components with :

Data $=$ Trend + Explanatory variables + constant + noise

It can be mathematically expressed by : $y_{t}=L x_{t}+D \mathrm{~d}_{t}+c+\mathrm{e}_{t}$

where $y_{t}$ is a vector $\mathrm{Nx} 1$ containing the values of the $\mathrm{N}$ time series at time $\mathrm{t}, x_{t}$ is a vector $\mathrm{Mx} 1$ containing the values of the $\mathrm{M}$ common trends at time $t, L$ is a matrix $\mathrm{NxM}$ containing the factor loadings on the $\mathrm{M}$ common trends, $d_{t}$ is a vector $\mathrm{Kx} 1$ with the values of the $\mathrm{K}$ covariates at time $t, D$ is a matrix NxK containing the unknown regression parameters between times series and covariates, $c$ is a $\mathrm{Nx} 1$ constant level parameter which allow each linear combination of common trends to move up or down and $e_{t}$ is the noise component distributed as a multivariate normal distribution with mean 0 and covariance matrix $\mathrm{R}$.

In this study, different hypotheses on the covariance matrix $(\mathrm{R})$ of the noise component were tested:

-Same variance and no covariance (diagonal-equal)

-Different variances and covariance (unconstrained)

-Same variance and covariance (equalvarcov).

DFA was first performed on standardized annual time series of environmental variables (i.e substracting the mean and dividing by the standard deviation) from 1993 to 2017 to investigate the main environmental patterns of the environmental system. Models were constructed with 1 
to 4 hidden trends, and the performance of the models have been evaluated according to AICc (AIC corrected for small samples) following Zuur et al., (2003). DFA can handle missing values in Chl-a and Convection time series between 1993 and 1997, but these two time series did not contribute to the construction of the common trends over those 5 years. Technically, the $\mathrm{L}$ matrix containing the factor loadings was replaced by $\mathrm{L} x \mathrm{~W}_{t}$ matrices, where $\mathrm{W}_{t}$ is a design matrix $\mathrm{N}_{t} \mathrm{x} N$ with $\mathrm{N}$ the number of variables and $\mathrm{N}_{t}$ the number of variables with non missing values at time $t . \mathrm{W}_{\mathrm{t}}$ contains 1 on the diagonal and 0 elsewhere (See Zuur et al., 2003 for further details). Then to investigate the relationship between small pelagics and environment, DFA was performed on annual time series of small pelagic biological data with annual environmental variables as covariates. Because missing values are not allowed in covariates time series, DFA was performed on the 10 small pelagic biological data (the abundance of sardine and the condition, biomass and size of sardine, anchovy and sprat) from 1998 to 2016 (the period of convection time series), with10 environmental covariates (Upwelling, Thermal fronts, Chl- $a$, Rhone flow, WEMO, SST, deep winter convection, $\mathrm{N}$ and $\mathrm{P}$ concentration and stratification). Biomass and abundance variables were first log transformed and then all the biological variables were standardized. All the combination of environmental covariates were tested (from 0 to all covariates in the same model). Once more, the performance of the models have been evaluated according to AICc. Finally, DFA was performed on biological data from 1993 to 2017, without covariates. As previously, variables were prior standardized and biomass and abundance were log transformed. Because no environmental covariates were retained in the best model from 1998 to 2016, we presented the results of the two DFA from 1993 to 2017 to investigate the links between small pelagic fishes and environment. 


\section{RESULTS}

\subsection{Analyses of the environmental times series}

\subsubsection{Seasonality}

Except for $\mathrm{P}$ concentration and the WeMO index, time series were highly seasonal, but not synchronous (Fig 2). SST (Fig 2a) and stratification (Fig 2b) were both highest in summer and their seasonal cycle was stable. In opposition, Chl-a (Fig 2c), Rhone flow (Fig 2d), N concentration (Fig 2e) and upwelling (Fig 2g) were highest during winter to early spring period. The timing of the Chl- $a$ peak was variable and occurred between February and May. Similar variability in the timing of the peaks was also detected for the Rhône flow, N Concentration and Upwelling, but between November and May this time. Thermal front index presented a different pattern with two seasonal peaks, in winter and summer. These outcomes were summarized in the Principal Component Analysis (PCA) on monthly averages (climatological time series) of all variables during the period 1998-2017 (ESM1-Fig S1). The two first principal components (PC) of the PCA accounted for $86 \%$ of the variability. As expected, SST and stratification covaried, with maximum values generally in August (ESM1-Fig S1), and were opposed to the upwelling index, the $\mathrm{N}$ nutrient concentration, the Rhone flow and the Chl- $a$ concentration, which peaked during winter and/or spring (ESM1-Fig S1). Thermal Front and P concentration were associated to the second axis because of the two seasonal peaks for the first one and the absence of seasonal cycle for the second. 
SST

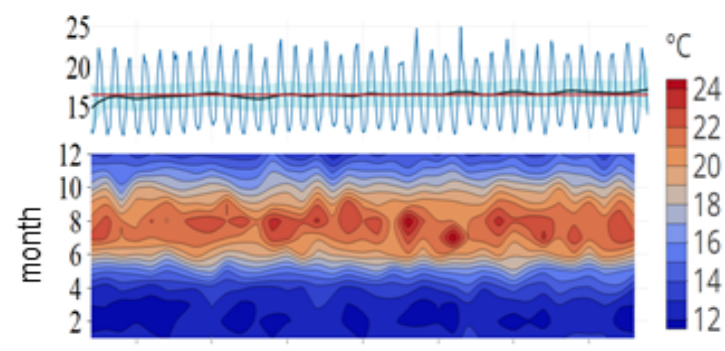

$\begin{array}{lllllll}1985 & 1990 & 1995 & 2000 & 2005 & 2010 & 2015\end{array}$ Rhone flow

2000

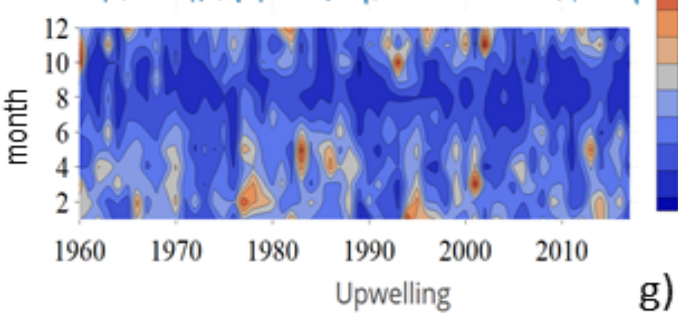

d)

m3.s

5000
4000

4000
3000

2000

1000

g)

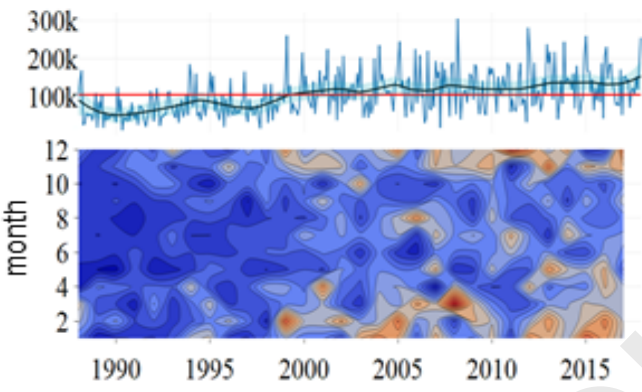

$\mathrm{m} 3 . \mathrm{s}$

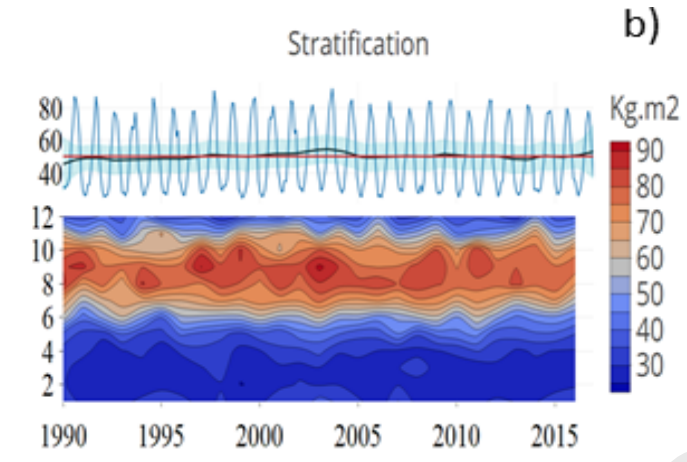

b)

Chlorophyll-a

c)

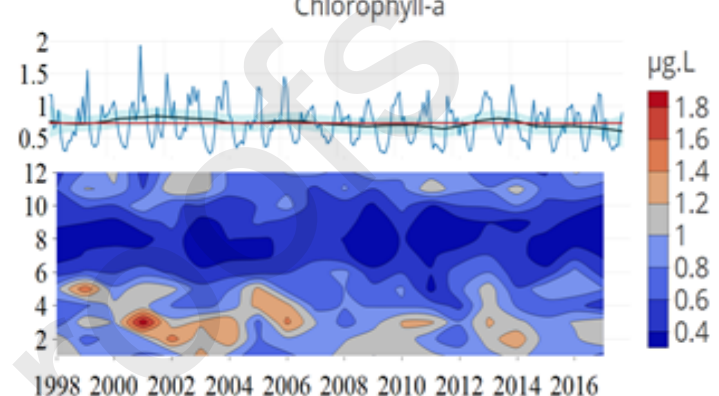

e)

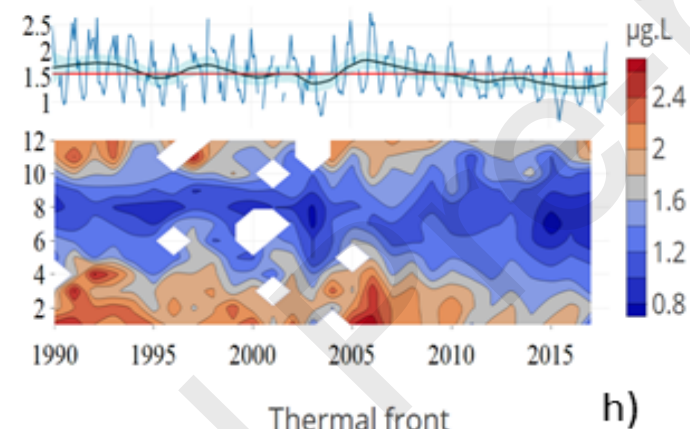

h)

front inde
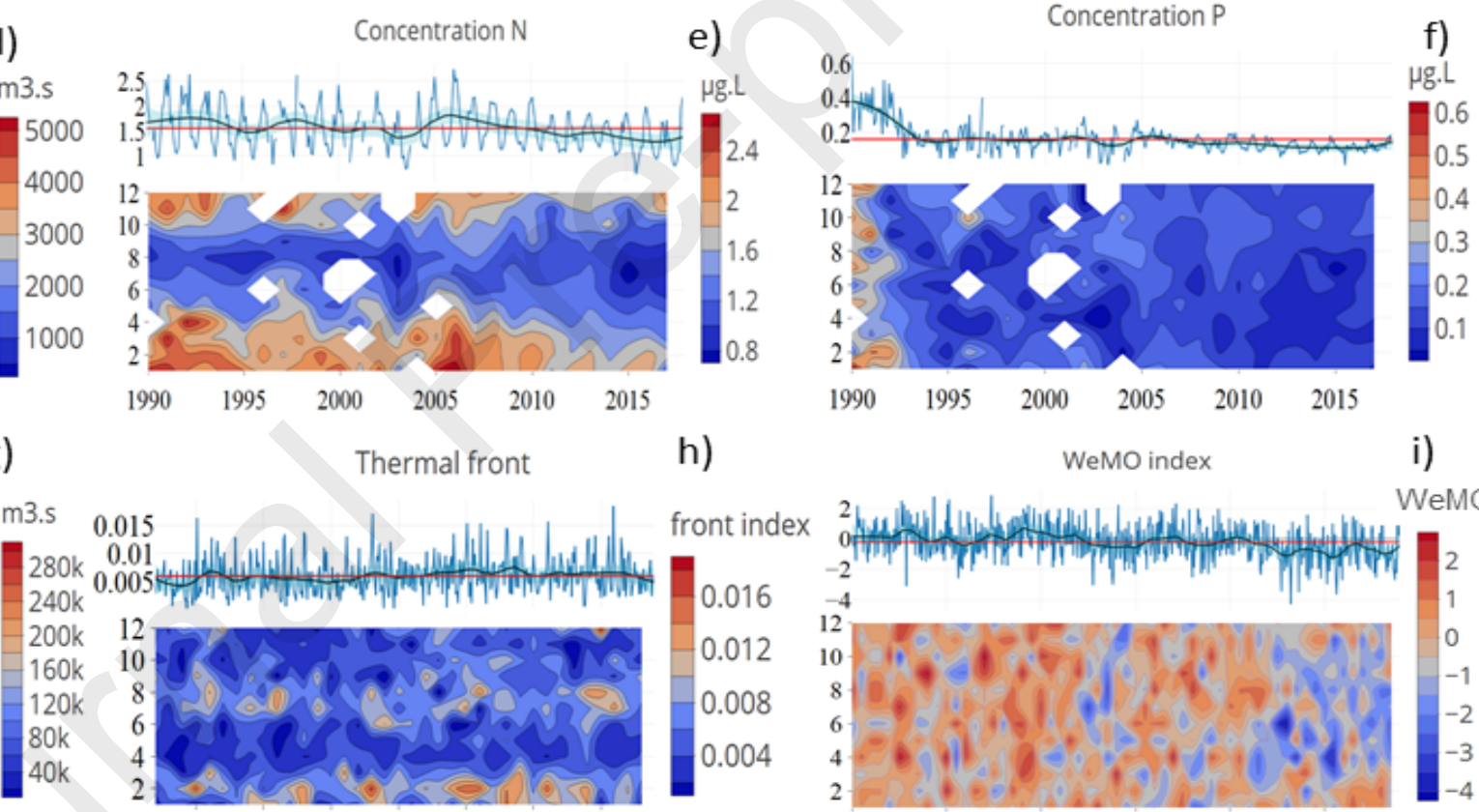

0.016

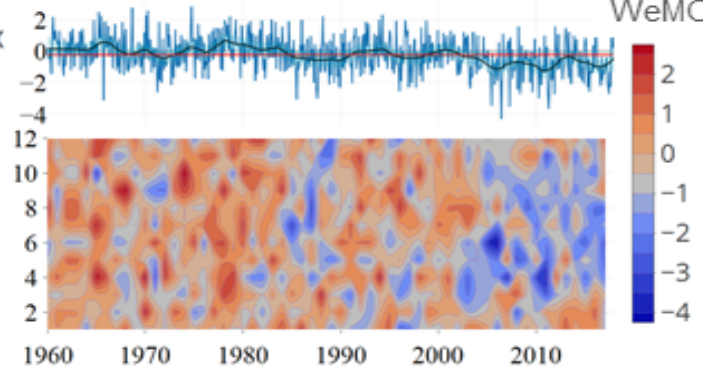

WeMO index

Figure 2: Contourplot of the monthly time series for the different environmental variables. The blue curve is the monthly mean time series and a loess smooth with a five years window size. The red line represent the mean of the time series for the entire period. 


\subsubsection{Trends and discontinuities}

Annual SST time series (Fig 3a) displayed a clear linear increase over the entire period (slope= $+0.019, \mathrm{p}<0.001$ ), ranging from $16.1^{\circ} \mathrm{C}$ in 1983 to $16.8^{\circ} \mathrm{C}$ in 2017 , while the stratification index (Fig 3b) was stable. No discontinuities were found in annual time series for both variables (Fig 3). The Chl- $a$ concentration monthly time series did not display any strong long term trend (Fig 2c), but the concentration during the late winter to spring period decreased since 2007 (Fig 2c). A breakpoint was detected in 2007 in the annual time series of Chl- $a$ (Fig 3c), which remains coherent with results on monthly time series, as spring and winter accounted for most of the annual phytoplanktonic biomass ( $32 \%$ and $31 \%$ respectively vs. $16 \%$ and $21 \%$ for summer and autumn respectively). Annual mean concentrations in Chl- $a$ were around $0.76 \pm 0.05 \mu$ g.L $\mathrm{L}^{-1}$ before 2007 and $0.71 \pm 0.05 \mu \mathrm{g} . \mathrm{L}^{-1}$ after (Fig 3c) and the difference was significant (Wilcoxon test, $\mathrm{p}=0.009)$.

The Rhône's flow presented a strong variability, both intra-annual with a marked seasonal cycle and inter-annual (Fig 2d). However, no breakpoint was detected and no long-term trend was observed. Concentration of $\mathrm{N}$ nutrient (Fig 2e) remained stable until 2005 and started to decrease in 2006 (Fig S2). A breakpoint was found in 2010 for the annual time series (Fig 3e). Concentration of P nutrient (Fig 2f) highly decreased between 1990 and 1995, as confirmed by the discontinuity in 1993 (Fig 3f), and values ranging from $0.36 \mathrm{mg} . \mathrm{L}^{-1}$ in 1990 to $0.15 \mathrm{mg} . \mathrm{L}^{-1}$ in 1995. The series then slightly decrease (slope $=-0.002, \mathrm{p}<0.001$ ), but no other breakpoint was detected. This decrease of nutrient concentrations induced a decrease of nutrient inputs, both for $\mathrm{N}$ and P nutrients (Figure 3-i and 3-j). However, breakpoints detected were different from those of the concentrations because of the variability of the river flow which also influence the inputs. Indeed, a breakpoint for N nutrient input was observed in 2001 and it was in 1994 and 2002 for P input. In brief, the Rhone system displayed high variability at both seasonal and 
inter-annual levels together with a significant impoverishment in nutrient concentration over time.

The upwelling index (Fig 3g) displayed a positive long-term trend (slope $=+2806, \mathrm{p}<0.001$ for the annual time series). Two discontinuities were detected in 1993 and 1999 (Fig 3g). For the thermal front index, a discontinuity was detected in 1997, with mean annual value of $0.0054 \pm$ 0.00075 before 1997 and $0.0065 \pm 0.00076$ after (Wilcoxon test, p-value $<0.001$ ). Finally, the WeMO which is the only large scale climatic variable of the dataset presented a significant decreasing trend (slope $=-0.035, \mathrm{p}<0.001)$ and a unique breakpoint was detected in 2002 .

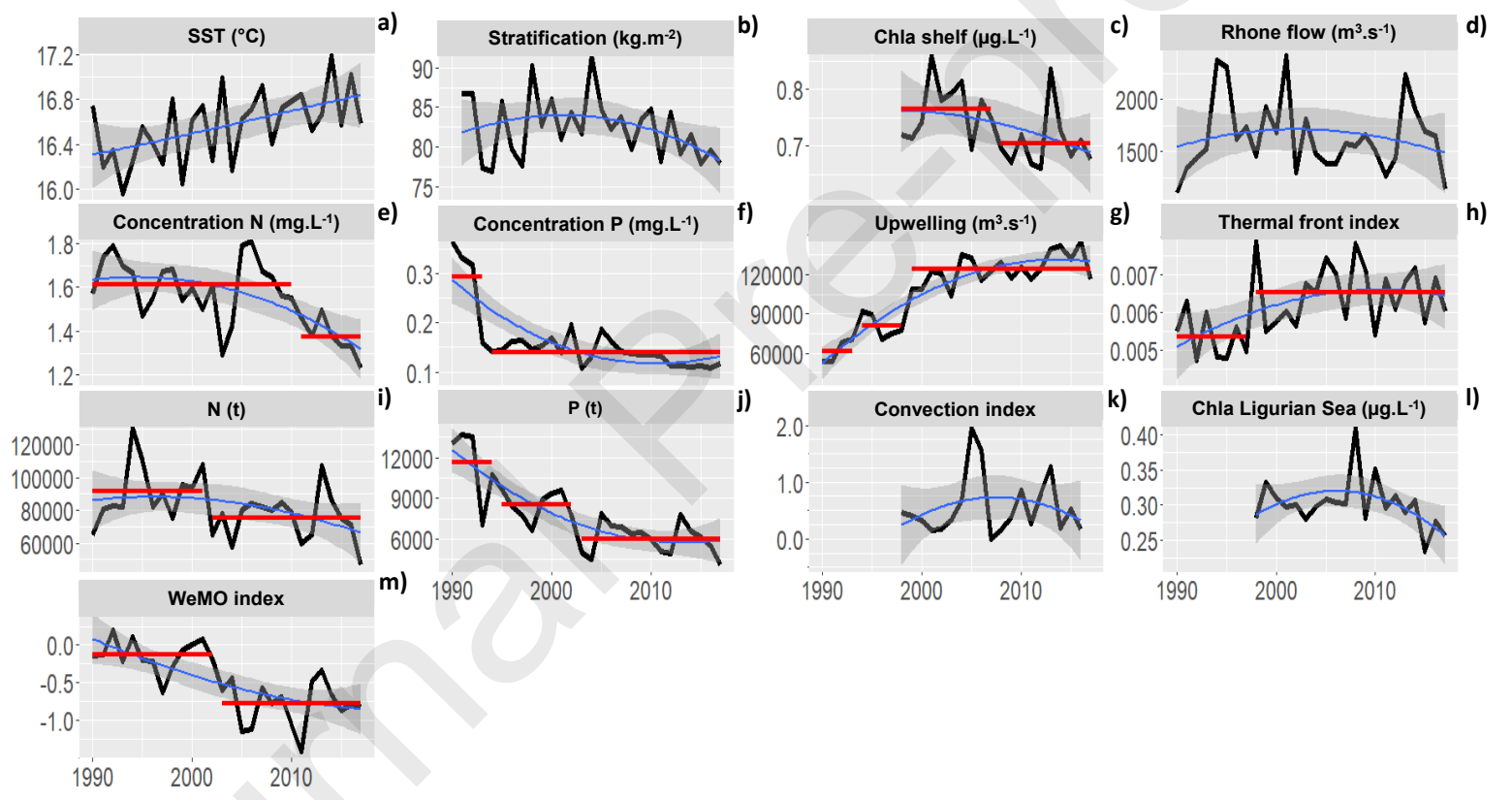

Figure 3: Annual time series of environmental variables. The blue curve is the loess smoothed 5 years trend and red lines represent the mean values between breakpoints. $N(t)$ and $P(t)$ represent the annual $N$ and $P$ nutrients inputs (in tons), calculated as the product between $N$ and $P$ nutrient concentrations and the river flow.

\subsection{Modelling the Chl- $a$ concentration}

To determine the principal drivers of Chl- $a$ variability on the Gulf of Lions shelf, a GLM analysis was run for the 2 cases described below (case 1 : with Rhone inflow and nutrient concentrations and case 2 : nutrient inputs). For the first case, only the Rhone's flow variable 
was retained in the best model $(\mathrm{p}<0.01)$, with both forward and backward stepwise selection. Residuals were normally distributed and the correlation between Chl- $a$ observed and predicted was significant at the $5 \%$ level $(r=0.55$, $p$-value $=0.015)$ (fig 4). The Rhone's flow alone explained about $30 \%$ of the variability of the Chl- $a$. For the second case, only the N nutrient inputs variable was kept, but it was only significant at the $10 \%$ level $(\mathrm{p}=0.055)$ with both forward and backward stepwise selection. Residuals were normally distributed but the correlation between Chl- $a$ observed and predicted was however lower and only significant at the $10 \%$ level $(\mathrm{r}=0.45$, $\mathrm{p}$-value $=0.055)($ ESM1-Fig S3).
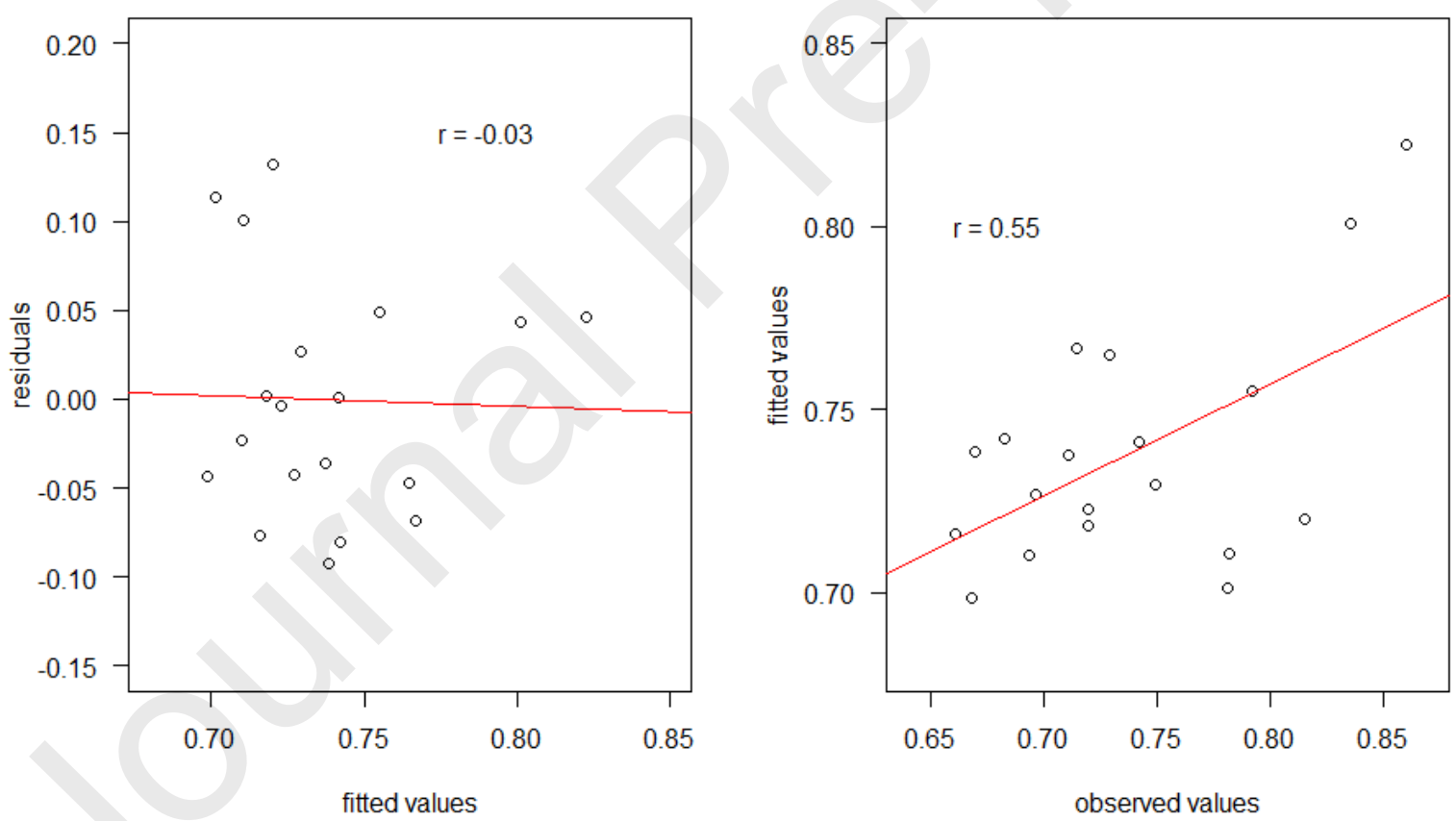

Figure 4: Diagnostic plots of glm analysis with the Rhone's flow as the only explanatory variable of Chl-a concentration. The left plot is residuals versus predicted Chl-a values and the right plot is predicted Chl-a values versus observed Chl-a values.

\subsection{The Dynamic Factor Analyses}


The first DFA was performed on the 10 environmental time series from 1993 to 2017 to investigate the underlying common trends of this dataset. To do so, we built 12 models with 1 to 4 common trends and tested 3 different hypothesis on the noise term matrix ("diagonal and equal", "equalvarcov" or "unconstrained"). The AICc values indicated that the model containing 2 common trends and a "diagonal and equal" noise matrix was the optimal one.

a)

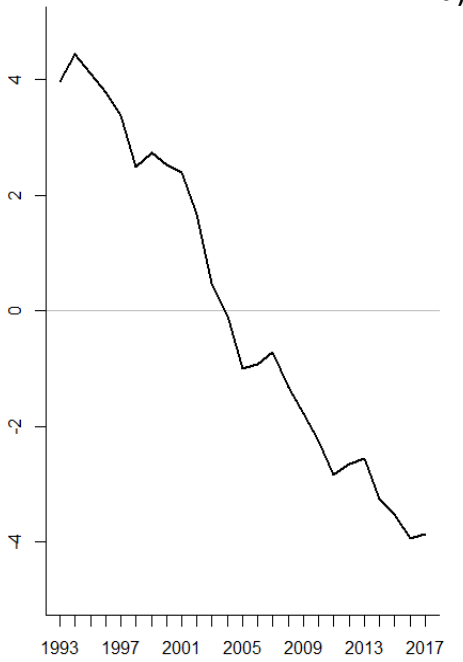

c)

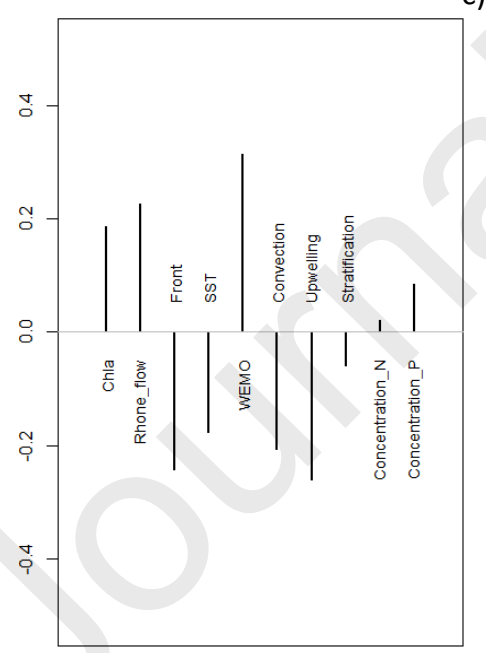

b)

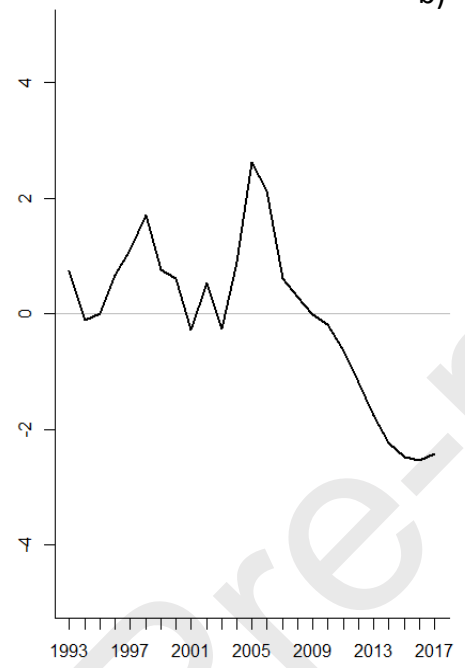

d)

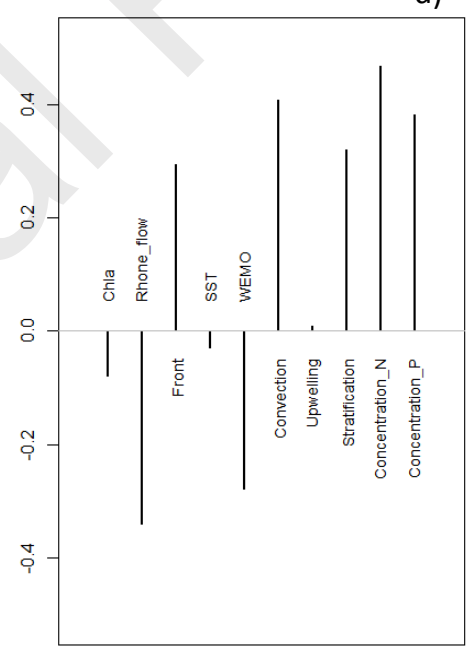

Figure 5: First (a) and second (b) common trends identified by the best model (lower AICc) of the DFA performed on the 10 environmental time series and the factor loadings of the different environmental time series for first (c) and second (d) common trend.

The first common trend (Figure 5-a) presented a strong linear and monotonous trend, which opposed Chl- $a$, Rhone flow and WEMO (displaying decreasing trends) to Thermal front, SST, 
winter convection and upwelling (displaying increasing trends). The second common trend (Figure 5-b) presented a different pattern with a quite stable period between 1993 and 2003, followed by a rapid increase during 2 years (peaking in 2005) and then by a sharp and continuous decrease until 2017. This common trend opposed mainly $\mathrm{N}$ and P concentrations, stratification, winter convection and thermal fronts (positively related to this trend) to Rhone flow and WEMO (negatively related to it). The fitted curves from the combination of these two common trends indicated that the environmental time series were reasonably fitted (ESM1-Fig S4). As expected, the fit was better for variables displaying high factor loadings, e.g. N concentrations, WEMO, winter convection, Rhône river flow, than for variables displaying rather low factor loadings $(<0.3)$ on both trends, e.g. SST, Chl- $a$ and upwelling.

\subsection{Small pelagic variability and link with environment}

Correlation test between biological variables reveled that abundance of sprat and abundance of anchovy were highly correlated to respectively biomass of sprat and biomass of anchovy. We then decided to remove the abundance of those two species from the analyses. For sprat condition and mean size, values estimated with less than 10 individuals were removed from the analyses. A second DFA was then performed on the 10 small pelagic biological time series (1998-2017) to identify the main patterns of variation of the population, using the environmental variables as exploratory variables, up to 4 common trends and 3 different matrices of noise component. After model selection based on AICc, the best model was the one with two common trends and a "diagonal and equal" $\mathrm{R}$ matrix, but did not retained any exploratory variables. Therefore, we could perform the DFA on longer biological time series (i.e., 1993-2017) without exploratory variables (some of them only starting in 1998). The best model identified by the AICc was also the one with two common trends and a "diagonal and equal" R matrix. The first common trend displayed an increase during the first three years, then 
a plateau at high values until 2000, followed by a sharp decrease until 2005, a rapid increase in 2006 followed by a new plateau at values close to zero until 2017 (Figure 6-a). This trend mainly opposed the biomass of anchovy and the mean size of sprat (positively related to this trend) to the biomass and abundance of sardine (negatively related to it). The second trend presented a stable (slightly increasing) period from 1993 to 2001, followed by a short decrease and then a rapid increase peaking in 2006 (Figure 6-b). The trend was then characterized by a strong and continuous decrease until 2012 at values 3 times lower than the beginning and stayed at these low levels until 2017. This trend opposed the biomass of sprat to the mean size of the three fish species, the condition of sardine and anchovy and the biomass of sardine (Figure 6d). All the variables displayed rather high factors loading $(>0.3)$ on at least one common trend, so that the fitted curves from the combination of these two common trends were quite good for the 10 biological time series (and better than for the environmental variables, which could indicate that the biological time series dataset was more homogeneous than the environmental one, ESM1-Fig S3).

If a continuous linear trend was only observed in the environmental variables, the second common trend of the DFA performed on the environmental variables was unexpectedly similar to the second trend of the DFA performed on the biological variables (Figure 7). Both trends displayed a stable phase from 1993 to 2003 , then 2 years of increase, followed by a sudden and sharp decrease (this decrease starting one year sooner in the DFA of the environmental variables than this on the biological variables, Figure 7) and finally by a stabilisation at low values in the most recent years. 

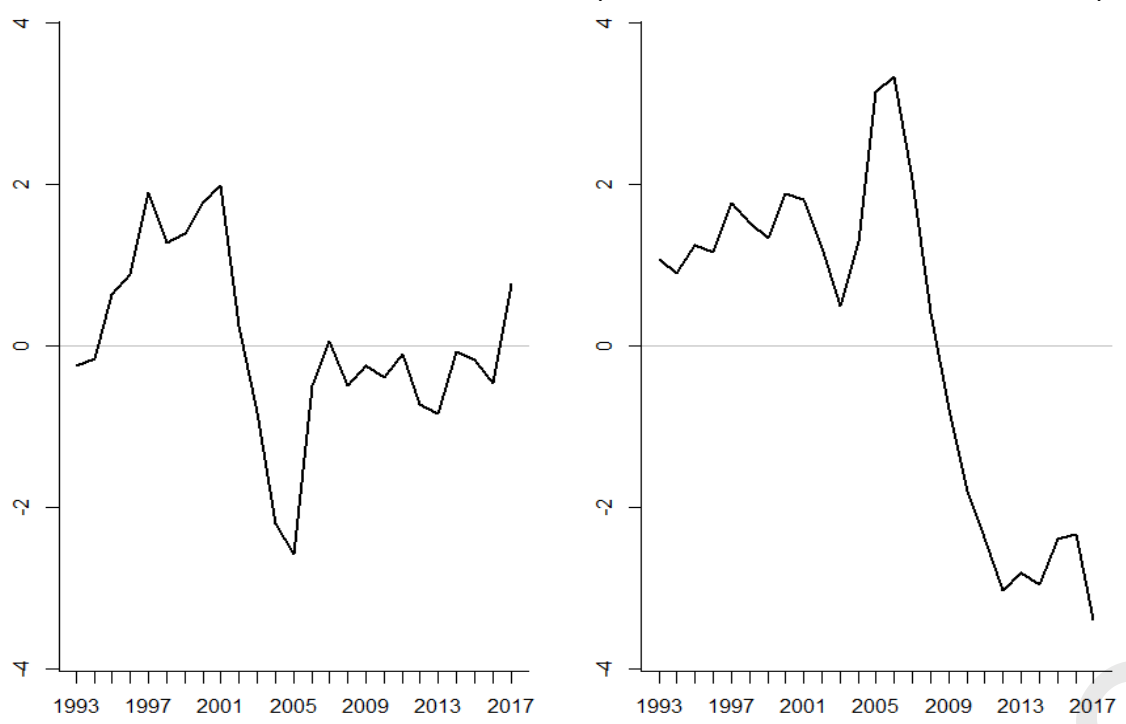

c)

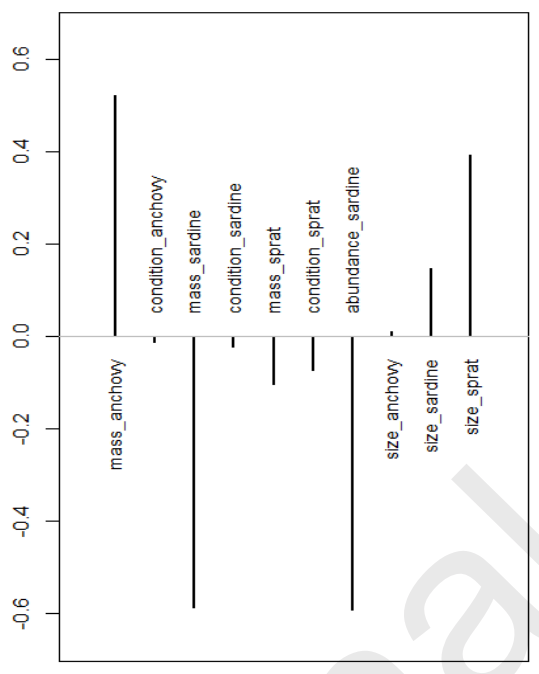

a)

b)

d)

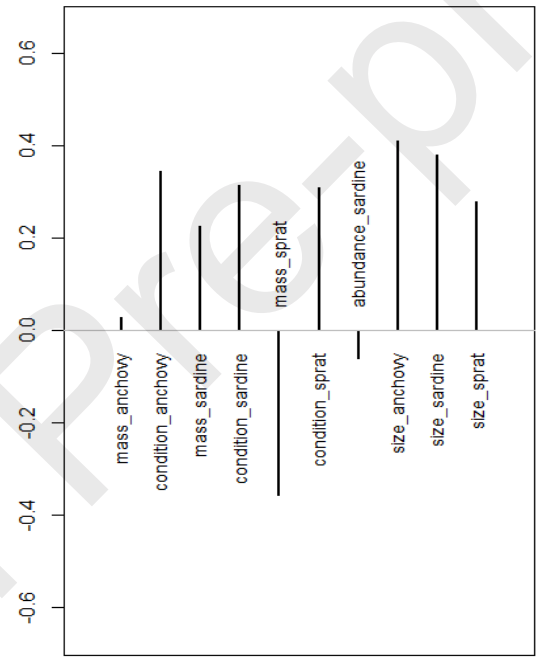

Figure 6: First (a) and second (b) common trends identified by the best model of the DFA performed on the 10 biological time series and the factor loadings of the different biological time series for first (c) and second (d) common trend. 


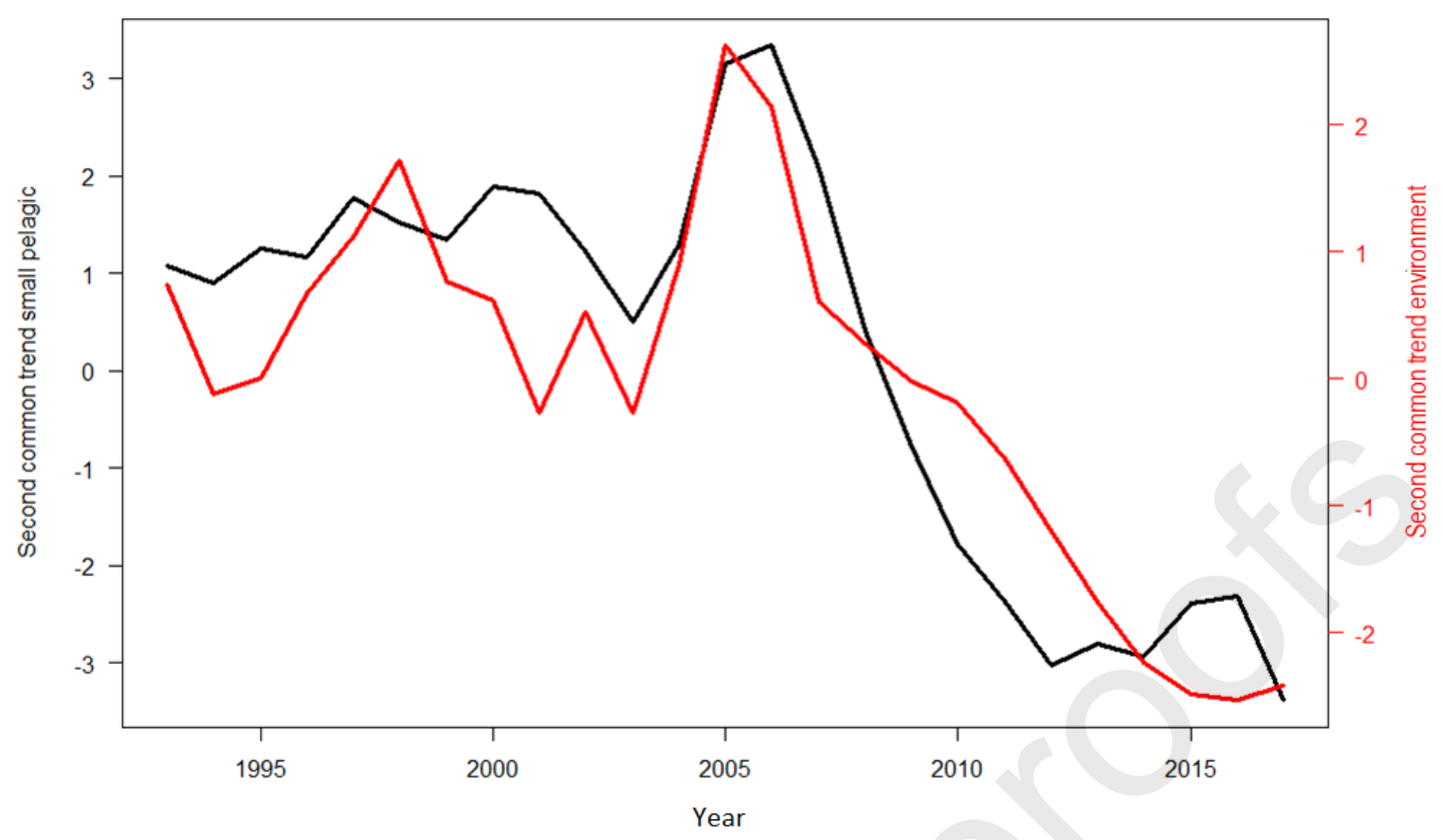

Figure 7: Second common trends of the DFAs performed on the environmental variables (red) and on the biological variables (black).

\section{DISCUSSION}

Small pelagic fish feed mainly on zooplankton and could thus be impacted by changes in the plankton community (i.e in quality or quantity), induced by environmental variability (bottomup control) (Csirke et al., 1996; Espinoza \& Bertrand, 2008). Because zooplankton time series were scarce in the study area, we used various oceanographic variables that are known to affect the plankton production in the Gulf of Lions and Chl- $a$ satellite data to depict and compare the main patterns of (co)variations of the environmental variables and of the small pelagic fish. If all the variables presented have already been studied, in relation with primary production in the area, it was the first time that the main forcing processes were pooled together, enabling us to partition the variance. However, the aim was not to have a detailed study of each process, but 
rather an overall understanding of the planktonic production and variability in this area. Such approach allowed us to investigate the hypothesis of a bottom-up control in the recent small pelagic fish crisis, albeit the absence of zooplankton time series. In this approach, time series were constructed considering the average over the entire shelf even if it is known that spatial heterogeneity is present within the shelf (Lefevre et al., 1997). Different points of the results will be discussed below as well as some potential implication for small pelagic fish.

\subsection{Environmental variability in the Gulf of Lions}

Seasonal variations are clearly marked on the shelf with a productive period in late winter and spring and an oligotrophic period in summer and early autumn. Chl- $a$ concentration peaks, which occur between January and May, also vary quite substantially in amplitude among years, between $0.82 \mu \mathrm{g} . \mathrm{L}^{-1}$ and $1.93 \mu \mathrm{g} . \mathrm{L}^{-1}$ for the studied period. An important result is the decrease of the Chl- $a$ concentration since 2007 with a breakpoint detected in the annual time series, indicating currently a lower phytoplanktonic biomass on the shelf. This decrease was mainly due to a decrease during the spring period, with weaker spring bloom on the shelf. This period is critical for the functioning of the system and changes of intensity could be linked to differences of community structure and then induce modification in the succession of plankton species and more generally in the food web (Mayot et al., 2017). Another significant decrease has been detected in the $\mathrm{N}$ and $\mathrm{P}$ nutrient concentration of the Rhone river. This could be explained by different regulation implemented during the past decades to improve water quality of French Rivers, such as change in fertilizer use, modifications in washing liquid composition, or an increase in water treatment on land, all viewed as improvement in terms of water quality, with a 3-fold decreases of N and P nutrient concentrations from 1990 to 1995 (Agence de l'eau, 2018). Nonetheless, these changes led to a diminution of the Rhone runoff inputs onto the continental shelf, as observed with the decreasing trends in the annual nutrient inputs time series and breakpoints detected in 2002 for N nutrient and in 1994 and 2002 for P nutrient. 
Other environmental variables displayed increasing trend over the period, such as SST (that could be related to the global warming as already shown in this area, see (Vargas-Yáñez et al., 2010), upwelling, which result of an intensification of Northerly winds in term of occurrence and intensity over the last decades and thermal fronts, partly impacted by the increase of coastal upwelling. If SST presented no breakpoints in the time series, both upwelling and thermal fronts had, in 1997 for fronts and 1993 and 1999 for upwelling.

Finally, others presented decreasing trends such as the WeMO index with a breakpoint in 2002. This large scale variable integrate different process and for this reason, different pattern of variation were shared with other variables such as the decreasing trend of stratification and Chla, generally positively related to WeMO, and the increase of SST generally opposed to WeMO values. The convection time series presented no clear trend over the period except 2 strong values in the mid 2000s.

As a whole, the environmental conditions in the Gulf of Lions displayed 2 main common trends highlighted by the DFA. The first one was a continuous linear change, similar to this observed for SST, upwelling, fronts and WeMO while the second trend, characterized by an abrupt discontinuity in the mid of the 2000 s, could not be entirely identified in any single environmental time series. Indeed, several series shared only parts of this trend and combining those different parts lead to the common trend identified. Those two common trends indicated that the environmental conditions in the Gulf of Lions have globally changed since the early 1990s, with more abrupt changes in the mid 2000s, which could have affected the planktonic and small pelagic fish communities of this area.

Results from the GLM analyses showed that the Rhone flow was the most important and only significant contributor of the annual Chl- $a$ production, explaining up to $30 \%$ of the variability in Chl- $a$ concentrations. The GLM outputs were also supported by the DFA performed on the environmental variables, both variables displaying factor loadings of the same sign on both 
common trends (and also of similar value on trend 1). Relationship between Chl- $a$ concentration and Rhone river flow was further rather obvious when considering extreme values. River flood, as in 2001, was related to a peak in Chl- $a$ concentration while low river flows, such as in 20112012, were related to low Chl- $a$ concentrations. As the annual time series of the Rhone river runoff did not display any significant long term trend (or breakpoints), we put forward that the decrease in Chl- $a$ concentration since 2007 could be mostly related to a decrease in nutrients inputs from the Rhone river (an hypothesis that nonetheless needs to be validated by further studies, possibly modeling studies). The GLM without the river flow, but including the nutrient inputs, indicated that variations in Chl- $a$ concentrations were best explained by the $\mathrm{N}$ nutrients inputs. This relation between variations in phytoplanktonic biomass on the Gulf of Lions shelf and the Rhone river discharge is in agreement with past studies, which estimated that $50 \%$ of the phytoplanktonic biomass was supported by Rhone river terrestrial inputs (Coste, 1974; Lefevre et al., 1997; Morel et al., 1990). Similarly, Macias et al., (2018) estimated, through modeling study, that the Rhone inputs would be now responsible for 20 to $40 \%$ of the Chl- $a$ concentration on the shelf, with a decreasing gradient from East to West.

In opposition to this impoverishment linked to Rhone river inputs, coastal upwellings, known to support phytoplanktonic production and, thus, pelagic fish populations (Brochier et al., 2018; Lips \& Lips, 2010; Schwartzlose \& Alheit, 1999) continuously increased through time because of stronger northerly winds. However, a detailed analysis (see ESM2) showed that while upwelling activity had a positive impact on phytoplanktonic biomass at a local scale (i.e. focusing on upwelling cell), this impact seemed not sufficient to act at the scale of the entire shelf. Moreover, Cassis upwelling area, which is the strongest upwelling cell in the Gulf of Lions, could have only a moderate impact because upwelled waters could be potentially carried away by the northern current (Millot, 1990). In the same line, this strong increase of the upwelling intensity did not seem to be strong enough to counterbalance the warming of the 
entire shelf, as also observed in some major coastal upwelling systems (Schwing \& Mendelssohn, 1997). While the correlation between upwelling and SST was negative at the daily and local scales (see the ESM2), annual SST continued to increase over the entire shelf of the Gulf of Lions, confirming the rapid and strong warming of the Western Mediterranean waters due to climate change (Vargas-Yáñez et al., 2010). For those reasons, we observed an increase of annual SST due to the global warming despite the increase of upwelling. Similarly, the spatial influence of the upwelling remained probably too limited to compensate the diminution in nutrient inputs from the Rhone river, leading to an overall impoverishment of the entire shelf. As the increase of fronts is partly due to the increase of upwelling, this hypothesis would then explain why the upwelling index and thermal fronts displayed opposite factor loadings on the DFA, and so opposite trend, compared to Chl- $a$ concentration. However, without the increasing trend of the upwelling, the decrease of Chl- $a$ would have probably been stronger. Finally, the DFA performed on the 10 environmental time series between 1993 and 2017 showed that the factor loadings on the first trend (i.e. the monotonic trend) of the WeMO was of the same sign as those of Rhone river flow and Chl- $a$, but opposed to those of SST. On the second trend, the factor loading of the WEMO was also of the same sign as those of Rhone river flow and opposed to those of stratification. All these observations were in accordance with (Martin-Vide \& Lopez-Bustins, 2006; Martín et al., 2012), which showed that positive phase of the WeMO index values were correlated with low SST and high river runoff (and vice versa).

\subsection{Comparison of variability in environmental conditions and small pelagic fish}

Small pelagic fish are key species of most pelagic ecosystems (including the Gulf of Lions) due to their central place in the food web, transferring energy from the lowest trophic levels (plankton) towards top-predators (Cury et al. 2000). Their short lifespan and high fecundity make them further strongly dependent on changes in environmental conditions (Bakun 1996). 
In the Gulf of Lions, the biomass, condition and size of sardine, as well as the condition of anchovy have strongly declined over the last decade, causing an important fishery crisis (Saraux et al., 2014, 2019). In the meantime, abundance and biomass of sprat strongly increased. The present study investigated potential common trends in these three small pelagic fish, using several variables (abundance, biomass, condition and size) from 1993 to 2017. The first common trend opposed anchovy biomass to sardine abundance and biomass, indicating that the 2 species had quite different dynamics. This opposition between the two species is a wellknown process in upwelling ecosystems (Alheit \& Niquen, 2004; Csirke et al., 1996). Moreover, this opposition could suggest different responses of the both species to environmental changes, maybe linked to differences in their diet (Brosset et al., 2016). This trend was associated to higher fluctuations of the population from the early 1990 s to the mid of the 2000 s and finally a third period with a low variability around intermediate levels until the end of the series. The second common trend, characterized by a strong and continuous decrease from the mid-2000s opposed the biomass of sprat to the mean size of the three fish species, the condition of sardine and anchovy and the biomass of sardine. This clearly confirms previous studies showing that the sprat might have profited from the decrease in size and condition of sardine and anchovy. Summarising the DFA results, it seems that the small pelagic fish community, represented by these three species, has significantly changed in the mid-2000s, with an increase in sprat biomass concurrent to a decrease in sardine and anchovy size and condition. Previous studies have suggested that such changes might be mediated by bottom-up control and a change in plankton (Brosset et al 2016), we further investigated the link between environment and small pelagic fishes through a DFA on the 10 biological time series using the environmental time series as covariates. However, after model selection based on AICc, the best model did not retain any exploratory variable. Such a result may reflect that only indirect links were present between the small pelagic fish community and environment, e.g. through the 
plankton community, or that the small pelagic fish community was not affected by a single given environmental variable, but rather by a global environmental change that would combine several abiotic processes. This second hypothesis was supported by the comparison of the 2 DFA (the environmental one and the biological one). While both datasets were totally independent, we obtained two very similar trends, showing a co-variation of the environment and the small pelagic community. Indeed, both second common trends displayed a rather stable phase from 1993 to 2003, then 2 years of increase, followed by a sudden and sharp decrease and then a stabilisation in the most recent years. As all statistical analyses, the results from the DFA do not demonstrate for any causal link between environmental conditions in the Gulf of Lions and the small pelagic fish community, but the synchrony of the two common trends questions. Interestingly, Brosset et al., (2016) found with isotopic analysis that the dietary of anchovy, sardine an sprat changed between 2005 and 2010 and remained the same since 2010 . This suggests that the plankton community have possibly been also impacted by those environmental changes. Our results thus tend to indicate that the environmental conditions have broadly changed in the Gulf of Lions, with a major change in the mid-2000s, affecting the Chl- $a$ concentration (which showed a breakpoint in 2007), but also the SST, the upwelling and frontal activities, the Rhone river discharge (and particularly the $\mathrm{N}$ and $\mathrm{P}$ nutrients inputs). Those changes could have affected plankton production and consequently the small pelagic fish community that displays similar patterns of variations as the environmental conditions. If changes in the food of small pelagic fish is our first hypothesis to explain changes observed in the small pelagic community, other ones could also be investigated. Indeed, the increase of sprat abundance could have led to an increase of competition with sardine and anchovy, inducing their decrease. Surprisingly, sprat seems to better accommodate than sardine and anchovy to environmental changes in the Gulf of Lions despite the global warming observed. An hypothesis is that with the increase of upwelling, cells of cold water are present near to the 
coast and favourable for sprat, allowing them to support increasing temperature. However, because sardine are strongly present at the coast (Saraux et al., 2014), we can assume that the competition between both species will increase with the increase of SST as the sprat could be more and more associated to those coastal areas of cold water. Moreover, this hypothesis could explain the differences observed between sardine and anchovy biomass, with the biomass of anchovy decreasing since early 2000s probably in response to environmental changes and the biomass of sardine decreasing abruptly in mid 2000s, possibly in response of the strong increase of the biomass of sprat. Those different results are then definitively in agreement with the hypothesis of a bottom-up control, but further analyses are needed to better understand the variability in the zooplankton community.

\subsection{Large scale interactions}

If environmental changes were observed at the scale of the Gulf of Lions with possible impact on small pelagic fish, changes at a larger scale are likely to have played a role on the Gulf of Lions. As already noted, global warming seems to strongly impact SST in the northwestern Mediterranean and possibly other key oceanic features that we did not investigate, such as the meso-scale circulation. In our study, we saw that the WeMO displayed high factor loadings on both common trends of the DFA performed on the environmental variables, indicating a link between the regional atmospheric circulation regime depicted by this index (see Martin-Vide and Lopez-Bustins 2006) and key oceanographic variables of the Gulf of Lions. Brosset et al., (2015) also found significant correlation between the WeMO index and sardine body condition, indicating that environmental variability at a larger scale could have indirect impact on the fish population dynamics. In the same way, (Martín et al., 2012) found a correlation between the annual WeMO index and the landings of sardine and anchovy of the Catalan coasts, with the hypothesis that positive WeMO phase were associated to a better recruitment and favorable condition for small pelagic fishes. 
Moreover, around 2006, changes have been observed in North Western Mediterranean Sea at different places and for different compartments of the ecosystems. In the Gulf of Trieste in Adriatic sea, a decrease of Chl- $a$ concentration was also observed in 2006, related to a decrease of river flow and nutrients inputs (Mozetič, et al. 2012). In the Ligurian sea, extrem convection event was observed in winter 2005-2006 and induced changes in the properties of the Ligurian Intermediate Water with a decrease of $\mathrm{O}_{2}$ concentration and an increase of Temperature and density (Coppola et al., 2018). Then, if no clear links have been made yet between those different changes, the mid-2000s seems to be critical in the Western and Central Mediterranean Sea.

\section{ACKNOWLEDGEMENTS}

We thank the captain and the crew of the RV "l'Europe" as well as all the scientists on board for their assistance during the PELMED surveys. The authors express their thanks to the three anonymous reviewers who helped to greatly improve the manuscript. Part of this research was funded through the MONALISA project, which was co-funded by the European Union and the French Ministry of Agriculture in the framework of the European Maritime and Fisheries Fund (EMFF, grant number PFEA280017DM0910001) and by France Filière Pêche (France).

\section{References}

Agence de l'eau. (2018). L'ÉTAT DES EAUX des bassins Rhône-Méditerranée et Corse.

Alheit, J., \& Niquen, M. (2004). Regime shifts in the Humboldt Current ecosystem. Progress in Oceanography, 60(2-4), 201-222. 
Bakun, A. (1996). Patterns in the ocean: ocean processes and marine population dynamics. California Sea Grant, in cooperation with Centro de Investigaciones Biologicas del Noroeste.

Bakun, A. (2006). Fronts and eddies as key structures in the habitat of marine fish larvae: opportunity, adaptive response and competitive advantage. Scientia Marina, 70(S2), $105-122$.

Barange, M., Coetzee, J., Takasuka, A., Hill, K., Gutierrez, M., Oozeki, Y., ... Agostini, V. (2009). Habitat expansion and contraction in anchovy and sardine populations. Progress in Oceanography, 83(1-4), 251-260.

Beaugrand, G., \& Reid, P. C. (2012). Relationships between North Atlantic salmon, plankton, and hydroclimatic change in the Northeast Atlantic. ICES Journal of Marine Science, 69(9), 1549-1562. Retrieved from http://dx.doi.org/10.1093/icesjms/fss153

Bourdeix, J. H., \& Hattab, T. (1985). PELMED-PELAGIQUES MEDITERRANÉE. https://doi.org/10.18142/19

Brochier, T., Auger, P. A., Pecquerie, L., Machu, E., Capet, X., Thiaw, M., ... Brehmer, P. (2018). Complex small pelagic fish population patterns arising from individual behavioral responses to their environment. Progress in Oceanography, 164(December 2017), 12-27. https://doi.org/10.1016/j.pocean.2018.03.011

Brosset, P., Fromentin, J. M., Ménard, F., Pernet, F., Bourdeix, J. H., Bigot, J. L., ... Saraux, C. (2015). Measurement and analysis of small pelagic fish condition: A suitable method for rapid evaluation in the field. Journal of Experimental Marine Biology and Ecology. https://doi.org/10.1016/j.jembe.2014.10.016

Brosset, P., Le Bourg, B., Costalago, D., BǍnaru, D., Van Beveren, E., Bourdeix, J. H., ... 
Saraux, C. (2016). Linking small pelagic dietary shifts with ecosystem changes in the Gulf of Lions. Marine Ecology Progress Series. https://doi.org/10.3354/meps 11796

Brosset, P., Lloret, J., Muñoz, M., Fauvel, C., Van Beveren, E., Marques, V., ... Saraux, C. (2016). Body reserves mediate trade-offs between life-history traits: New insights from small pelagic fish reproduction. Royal Society Open Science. https://doi.org/10.1098/rsos.160202

Brosset, P., Ménard, F., Fromentin, J.-M., Bonhommeau, S., Ulses, C., Bourdeix, J.-H., ... Saraux, C. (2015). Influence of environmental variability and age on the body condition of small pelagic fish in the Gulf of Lions. Marine Ecology Progress Series, 529, 219231.

Caverivière, A., \& Demarcq, H. (2002). Indices d'abondance du poulpe commun et intensité de l'upwelling côtier au Sénégal. Caverivière A., Thiam M., Jouffre D.(Éds)-Le Poulpe Commun Octopus Vulgaris. Sénégal et Côtes Nord-Ouest Africaines. Editions IRD, Paris, Colloques et Séminaires, 143-156.

Cayula, J.-F., \& Cornillon, P. (1992). Edge detection algorithm for SST images. Journal of Atmospheric and Oceanic Technology, 9(1), 67-80.

Chambers, R. C., \& Trippel, E. A. (2012). Early life history and recruitment in fish populations (Vol. 21). Springer Science \& Business Media.

Coll, M., Albo-Puigserver, M., Navarro, J., Palomera, I., \& Dambacher, J. M. (2018). Who is to blame? Plausible pressures on small pelagic fish population changes in the northwestern Mediterranean Sea. Marine Ecology Progress Series.

Coppola, L., Legendre, L., Lefevre, D., Prieur, L., Taillandier, V., \& Riquier, E. D. (2018). Seasonal and inter-annual variations of dissolved oxygen in the northwestern 
Mediterranean Sea (DYFAMED site). Progress in Oceanography, 162, 187-201.

Costalago, D., Navarro, J., Álvarez-Calleja, I., \& Palomera, I. (2012). Ontogenetic and seasonal changes in the feeding habits and trophic levels of two small pelagic fish species. Marine Ecology Progress Series. https://doi.org/10.3354/meps09751

Coste, B. (1974). Role des apports nutritifs mineraux rhodaniens sur la production organique des eaux du Golfe du Lion. Tethys, 6, 727-740.

Csirke, J., Guevara-Carrasco, R., Cárdenas, G., Niquen, M., \& Chipollini, A. (1996). State of the resources anchoveta (Engraulis ringens) and sardine (Sardinops sagax) in early 1994 and perspective for fishing in Peru with special emphasis on the Centre and North regions of the Peruvian coast. Bol Inst Mar Peru, 15, 1-23.

Cury, P., Bakun, A., Crawford, R. J. M., Jarre, A., Quinones, R. A., Shannon, L. J., \& Verheye, H. M. (2000). Small pelagics in upwelling systems: patterns of interaction and structural changes in "wasp-waist” ecosystems. ICES Journal of Marine Science, 57(3), 603-618.

Cushing, D. H. (1990). Plankton production and year-class strength in fish populations: an update of the match/mismatch hypothesis. In Advances in marine biology (Vol. 26, pp. 249-293). Elsevier.

Demarcq, H., \& Wald, L. (1984). La dynamique superficielle du panache du Rhône d'après l'imagerie infrarouge satellitaire. Oceanologica Acta, 7(2), 159-162.

Doray, M. (2012). Pelagic fish stock assessment by acoustic methods at Ifremer.

Espinoza, P., \& Bertrand, A. (2008). Revisiting Peruvian anchovy (Engraulis ringens) trophodynamics provides a new vision of the Humboldt Current system. Progress in Oceanography, 79(2-4), 215-227. 
Estournel, C., Testor, P., Damien, P., D’Ortenzio, F., Marsaleix, P., Conan, P., ... Lellouche, J. (2016). High resolution modeling of dense water formation in the north-western Mediterranean during winter 2012-2013: Processes and budget. Journal of Geophysical Research: Oceans, 121(7), 5367-5392.

Franks, P. J. S. (1992). Sink or swim: Accumulation of biomass at fronts. Marine Ecology Progress Series. Oldendorf, 82(1), 1-12.

Fraysse, M., Pinazo, C., Faure, V. M., Fuchs, R., Lazzari, P., Raimbault, P., \& Pairaud, I. (2013). Development of a 3D coupled physical-biogeochemical model for the Marseille coastal area (NW Mediterranean Sea): What complexity is required in the coastal zone? PloS One, 8(12), e80012.

Gohin, F. (2002). International Journal of A five channel chlorophyll concentration algorithm applied to SeaWiFS data processed by SeaDAS in coastal waters. International Journal Remote Sensing, 23(January), 1639-1661.

Gohin, F., Loyer, S., Lunven, M., Labry, C., Froidefond, J. M., Delmas, D., ... Herbland, A. (2005). Satellite-derived parameters for biological modelling in coastal waters: Illustration over the eastern continental shelf of the Bay of Biscay. Remote Sensing of Environment, 95(1), 29-46. https://doi.org/10.1016/j.rse.2004.11.007

Herrmann, M., Auger, P., Ulses, C., \& Estournel, C. (2017). Long-term monitoring of ocean deep convection using multisensors altimetry and ocean color satellite data. Journal of Geophysical Research: Oceans, 122(2), 1457-1475.

Herrmann, M., Diaz, F., Estournel, C., Marsaleix, P., \& Ulses, C. (2013). Impact of atmospheric and oceanic interannual variability on the Northwestern Mediterranean Sea pelagic planktonic ecosystem and associated carbon cycle. Journal of Geophysical Research: Oceans. https://doi.org/10.1002/jgrc.20405 
Herrmann, M., Estournel, C., Adloff, F., \& Diaz, F. (2014). Impact of climate change on the northwestern Mediterranean Sea pelagic planktonic ecosystem and associated carbon cycle. Journal of Geophysical Research C: Oceans. https://doi.org/10.1002/2014JC010016

Kleiber, C., Hornik, K., Leisch, F., \& Zeileis, A. (2002). strucchange: An R package for testing for structural change in linear regression models. Journal of Statistical Software, $7(2), 1-38$.

Kodama, T., Wagawa, T., Ohshimo, S., Morimoto, H., Iguchi, N., Fukudome, K., ... Yasuda, T. (2018). Improvement in recruitment of Japanese sardine with delays of the spring phytoplankton bloom in the Sea of Japan. Fisheries Oceanography, 27(4), 289-301.

Kudela, R. M., Cochlan, W. P., Peterson, T. D., \& Trick, C. G. (2006). Impacts on phytoplankton biomass and productivity in the Pacific Northwest during the warm ocean conditions of 2005. Geophysical Research Letters, 33(22).

Larkin, P. A. (1996). Concepts and issues in marine ecosystem management. Reviews in Fish Biology and Fisheries, 6(2), 139-164.

Le Cren, E. D. (1951). The length-weight relationship and seasonal cycle in gonad weight and condition in the perch (Perca fluviatilis). The Journal of Animal Ecology, 201-219.

Lefevre, D., Minas, H. J., Minas, M., Robinson, C., Williams, P. J. L. B., \& Woodward, E. M. S. (1997). Review of gross community production, primary production, net community production and dark community respiration in the Gulf of Lions. Deep Sea Research Part II: Topical Studies in Oceanography, 44(3-4), 801-832.

Lindegren, M., Checkley, D. M., Rouyer, T., MacCall, A. D., \& Stenseth, N. C. (2013). Climate, fishing, and fluctuations of sardine and anchovy in the California Current. 
Proceedings of the National Academy of Sciences, 110(33), 13672-13677.

Lips, I., \& Lips, U. (2010). Phytoplankton dynamics affected by the coastal upwelling events in the Gulf of Finland in July-August 2006. Journal of Plankton Research. https://doi.org/10.1093/plankt/fbq049

Macias, D., Garcia-Gorriz, E., \& Stips, A. (2018). Major fertilization sources and mechanisms for Mediterranean Sea coastal ecosystems. Limnology and Oceanography, 63(2), 897914.

Martin-Vide, J., \& Lopez-Bustins, J. (2006). The western Mediterranean oscillation and rainfall in the Iberian Peninsula. International Journal of Climatology: A Journal of the Royal Meteorological Society, 26(11), 1455-1475.

Martín, P., Sabatés, A., Lloret, J., \& Martin-Vide, J. (2012). Climate modulation of fish populations: the role of the Western Mediterranean Oscillation (WeMO) in sardine (Sardina pilchardus) and anchovy (Engraulis encrasicolus) production in the northwestern Mediterranean. Climatic Change, 110(3-4), 925-939.

Mayot, N., D’Ortenzio, F., Uitz, J., Gentili, B., Ras, J., Vellucci, V., ... Claustre, H. (2017). Influence of the Phytoplankton Community Structure on the Spring and Annual Primary Production in the Northwestern Mediterranean Sea. Journal of Geophysical Research: Oceans. https://doi.org/10.1002/2016JC012668

Millot, C. (1999). Circulation in the western Mediterranean Sea. Journal of Marine Systems, $20(1-4), 423-442$.

Millot, C. (1979). Wind induced upwellings in the Gulf of Lions. Oceanologica Acta, 2(3), 261-274. Retrieved from http://archimer.ifremer.fr/doc/00122/23335/

Millot, Claude. (1990). The gulf of Lions' hydrodynamics. Continental Shelf Research, 10(9- 
11), 885-894.

Morel, A, Bricaud, A., André, J. M., \& Pelaez-Hudlet, J. (1990). Spatial/temporal evolution of the Rhone plume as seen by CZCS imagery-Consequences upon the primary production in the Gulf of Lions. Water Pollution Research Reports, 20, 45-62.

Morel, André, \& Prieur, L. (1977). Analysis of variations in ocean color 1. Limnology and Oceanography, 22(4), 709-722.

Mozetič, P., Francé, J., Kogovšek, T., Talaber, I., \& Malej, A. (2012). Plankton trends and community changes in a coastal sea (northern Adriatic): bottom-up vs. top-down control in relation to environmental drivers. Estuarine, Coastal and Shelf Science, 115, 138-148.

Petrenko, A. A. (2003). Variability of circulation features in the Gulf of Lion NW Mediterranean Sea. Importance of inertial currents. Oceanologica Acta, 26(4), 323-338.

Queiros, Q., Fromentin, J.-M., Astruc, G., Bauer, R. K., \& Saraux, C. (2018). Dolphin predation pressure on pelagic and demersal fish in the northwestern Mediterranean Sea. Marine Ecology Progress Series, 603, 13-27.

Roa-Pascuali, L., Demarcq, H., \& Nieblas, A. E. (2015). Detection of mesoscale thermal fronts from $4 \mathrm{~km}$ data using smoothing techniques: Gradient-based fronts classification and basin scale application. Remote Sensing of Environment, 164, 225-237. https://doi.org/10.1016/j.rse.2015.03.030

Ross, O. N., Fraysse, M., Pinazo, C., \& Pairaud, I. (2016). Impact of an intrusion by the Northern Current on the biogeochemistry in the eastern Gulf of Lion, NW Mediterranean. Estuarine, Coastal and Shelf Science, 170, 1-9. https://doi.org/10.1016/j.ecss.2015.12.022

Rykaczewski, R. R. (2018). Changes in mesozooplankton size structure along a trophic 
gradient in the California Current Ecosystem and implications for small pelagic fish. Marine Ecology Progress Series.

Salat, J. (1996). Review of hydrographic environmental factors that may influence anchovy habitats in northwestern Mediterranean. SCIENTIA MARINA, 60 (Supl., 21-32.

Saraux, C., Fromentin, J.-M., Bigot, J.-L., Bourdeix, J.-H., Morfin, M., Roos, D., .. Bez, N. (2014). Spatial Structure and Distribution of Small Pelagic Fish in the Northwestern Mediterranean Sea. PLoS ONE. https://doi.org/10.1371/journal.pone.0111211

Saraux, C., Van Beveren, E., Brosset, P., Queiros, Q., Bourdeix, J.-H., Dutto, G., ... Fromentin, J.-M. (2019). Small pelagic fish dynamics: A review of mechanisms in the Gulf of Lions. Deep Sea Research Part II: Topical Studies in Oceanography.

Schwartzlose, R. A., \& Alheit, J. (1999). Worldwide large-scale fluctuations of sardine and anchovy populations. African Journal of Marine Science, 21.

Schwing, F. B., \& Mendelssohn, R. (1997). Increased coastal upwelling in the California Current System. Journal of Geophysical Research, 102(C2), 3421-3438. Retrieved from http://www.agu.org/pubs/crossref/1997/96JC03591.shtml

Simoncelli, S., Fratianni, C., Pinardi, N., Grandi, A., Drudi, M., Oddo, P., \& Dobricic, S. (2014). Mediterranean Sea physical reanalysis (MEDREA 1987-2015)(Version 1).

Skjoldal, H. R., Gjøsæter, H., \& Loeng, H. (1992). The Barents Sea ecosystem in the 1980s: ocean climate, plankton, and capelin growth. In ICES Marine Science Symposia (Vol. 195, pp. 278-290).

Stenseth, N. C., \& Mysterud, A. (2005). Weather packages: finding the right scale and composition of climate in ecology. Journal of Animal Ecology, 74(6), 1195-1198.

Stenseth, N. C., Ottersen, G., Hurrell, J. W., Mysterud, A., Lima, M., Chan, K., ... 
Ådlandsvik, B. (2003). Studying climate effects on ecology through the use of climate indices: the North Atlantic Oscillation, El Nino Southern Oscillation and beyond. Proceedings of the Royal Society of London. Series B: Biological Sciences, 270(1529), 2087-2096.

Team, R. C. (2018). R Core Team (2018). R: A language and environment for statistical computing. R Foundation for Statistical Computing, Vienna. ISBN 3-900051-07-0. http://www. R-project. org.

Toresen, R., \& Østvedt, O. J. (2000). Variation in abundance of Norwegian spring-spawning herring (Clupea harengus, Clupeidae) throughout the 20th century and the influence of climatic fluctuations. Fish and Fisheries, 1(3), 231-256.

Van Beveren, E., Bonhommeau, S., Fromentin, J.-M., Bigot, J.-L., Bourdeix, J.-H., Brosset, P., ... Saraux, C. (2014). Rapid changes in growth, condition, size and age of small pelagic fish in the Mediterranean. Marine Biology. https://doi.org/10.1007/s00227-0142463-1

Van Beveren, E., Fromentin, J.-M., Bonhommeau, S., Nieblas, A.-E., Metral, L., Brisset, B., ... Saraux, C. (2017). Predator-prey interactions in the face of management regulations: changes in Mediterranean small pelagic species are not due to increased tuna predation. Canadian Journal of Fisheries and Aquatic Sciences, 74(9), 1422-1430.

Van Beveren, E., Fromentin, J. M., Rouyer, T., Bonhommeau, S., Brosset, P., \& Saraux, C. (2016). The fisheries history of small pelagics in the Northern Mediterranean. ICES Journal of Marine Science. https://doi.org/10.1093/icesjms/fsw023

Van Beveren, E., Keck, N., Fromentin, J. M., Laurence, S., Boulet, H., Labrut, S., ... Saraux, C. (2016). Can pathogens alter the population dynamics of sardine in the NW Mediterranean? Marine Biology. https://doi.org/10.1007/s00227-016-3015-7 
Vargas-Yáñez, M., Moya, F., García-Martínez, M. del C., Tel, E., Zunino, P., Plaza, F., ...

Serra, M. (2010). Climate change in the Western Mediterranean sea 1900-2008. Journal of Marine Systems, 82(3), 171-176.

Woodson, C. B., \& Litvin, S. Y. (2015). Ocean fronts drive marine fishery production and biogeochemical cycling. Proceedings of the National Academy of Sciences, 112(6), $1710-1715$.

Zuur, A. F., Fryer, R. J., Jolliffe, I. T., Dekker, R., \& Beukema, J. J. (2003). Estimating common trends in multivariate time series using dynamic factor analysis.

Environmetrics: The Official Journal of the International Environmetrics Society, 14(7), $665-685$. 
Highligths

- Rhone river nutrients concentrations significantly decreased since 1990.

- Rhone river inputs are the main driver of Chl- $a$ in the Gulf of Lions shelf area.

- Changes were observed in the environment and small pelagic fish population in mid 2000s.

- Small pelagic community and environmental system of the Gulf of Lions presented the same patterns of variation. 
The authors state that they have no conflict of interest 